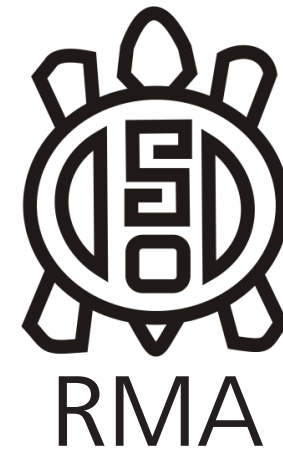

Dossier

Wichí: El mundo

\title{
Toponimia de los wichís del Noroeste de Formosa, Argentina
}

\author{
Toponymy of the Wichi of Northwest Formosa, Argentina
}

Marco Flamini*

*IMBIV, CONICET, Universidad Nacional de Córdoba, Argentina. E-mail: flaminim@gmail.com

\begin{abstract}
Resumen
El artículo presenta un estudio toponímico, donde además de recopilar topónimos, traducirlos y localizarlos en un mapa, se analizan las explicaciones sobre los orígenes de cada uno y se compara el repertorio obtenido con otros de zonas aledañas. Para ello, se desarrolló un mapeo participativo en conjunto con los habitantes de las aldeas de Pescado Negro y Los Pocitos-Tay'ú y se analizó material inédito de entrevistas y relatos recogidos in situ. Los nombres de los lugares analizados evocan narrativas que describen un ambiente natural y social dinámico, habitado por multiplicidad de seres (humanos y no humanos, físicos y metafísicos) vinculados íntimamente en un constante ciclo de vida y muerte, degeneración y renovación. El mapa de topónimos wichí es mucho más que una representación cartográfica del paisaje, aborda diversos tópicos significativos para los wichís y guarda en sí mismo testimonios de las múltiples dimensiones de la experiencia humana sobre el territorio.
\end{abstract}

Palabras clave: Gran Chaco; Wichí; Territorio; Toponimia; Narrativa.

\begin{abstract}
This article presents a toponymic study, where in addition to collecting toponyms, translating and locating them on a map, the explanations of the origins of each one are analysed and contextualized and the accounts obtained are compared with those of neighbouring areas. For this purpose a participatory mapping is employed, carried out together with inhabitants of the villages of Pescado Negro and Los Pocitos-Tay'ú, and unpublished material from interviews and stories collected in situ are analysed. The studied toponyms evoke narratives that describe a dynamic natural and social environment, inhabited by a multiplicity of beings (human and non-human, physical and metaphysical) intimately linked in a constant cycle of life and death, degeneration and renewal. The Wichi toponymic map is far more than a cartographic representation of the landscape, it addresses many significant topics for the Wichi and holds testimonies of the multidimensional human experience within the territory.
\end{abstract}

Keywords: Gran Chaco; Wichi; Territory; Toponymy; Narrative.

\section{Introducción}

Los wichi son un pueblo indígena que habita en el Chaco Semiárido de Argentina en las provincias de Salta, Formosa y Chaco, y que se encuentra cultural, histórica y lingüísticamente ligado a los w'enhayey de Bolivia. Poseen una lengua propia, el wichi-lhämtes, que pertenece a la familia lingüística mataco-mataguaya (Fabre, 2005). En tiempos pasados, estaban organizados en pequeños grupos nómadas que recorrían extensas áreas, en donde practicaban la caza, la pesca y la recolección, y en menor medida la agricultura. Conocían a la perfección las áreas que recorrían, y los lugares que les resultaban significativos eran nombrados según distintos criterios.

Los nombres de los lugares wichís guardan historias en las que están representadas memorias colectivas, prácticas sociales y modos de entender el mundo. Cuando se otorgan nombres al espacio, se lo transforma simbólica y materialmente en un territorio culturalmente organizado, y en ese mismo acto se ponen en juego elementos de la identidad colectiva y su dinámica en el tiempo (Censabella, 2009; Palmer, 2005, p. 41). Además, los wichís continúan buscando en las tierras que históricamente habitaron, los alimentos, las medicinas, los combustibles, y otros elementos que les permiten sostener su economía, y por tanto, el territorio es considerado un "elemento trascendental, que da soporte a la vida" (Arenas, 2003: 76).

El marco jurídico internacional y nacional sobre los derechos de los pueblos indígenas garantiza una serie de derechos especiales sobre los territorios y las lenguas 
nativas. A nivel internacional se destacan: el Convenio 169 de la Organización Internacional del Trabajo, la Declaración de las Naciones Unidas sobre los Derechos de los Pueblos Indígenas y la Convención Americana sobre Derechos Humanos. En líneas generales, los tres establecen el derecho de los pueblos indígenas sobre sus territorios tradicionales, sobre los recursos naturales allí presentes y promueven el respeto y la educación en lenguas indígenas. Existe además una versión provisoria de la Declaración Universal de Derechos Lingüísticos, firmada en Barcelona en 1996, que destaca la importancia del vínculo entre las comunidades lingüísticas y sus territorios, y los derechos al uso de los "topónimos autóctonos" en los ámbitos privados, públicos y oficiales.

A nivel nacional, en la reforma de la Constitución Nacional del año 1994, se incluyeron por primera vez en la Carta Magna los derechos de los pueblos indígenas en el artículo 75 (inciso 17): el reconocimiento de su preexistencia étnica y cultural, el derecho a una educación intercultural bilingüe, el reconocimiento de la posesión y propiedad comunitaria "de las tierras que tradicionalmente ocupan", y hasta se asegura la participación indígena en la gestión de los recursos naturales. Desgraciadamente, y a pesar de la abundante normativa nacional e internacional vigente en el país, el esfuerzo que dedicaron los distintos gobiernos nacionales y provinciales no llegó ni a frenar los eternos abusos de los que fueron históricamente víctimas los aborígenes, ni a garantizar los derechos a disponer de sus territorios tradicionales (como tampoco los derechos humanos básicos como el acceso al agua y la salud) (Arenas, 2003 p. 90; Matarrese, 2019; Palmer, 2005, pp. 3-5.; Salamanca, 2012).

En lo que respecta a los wichís formoseños, se han obtenido algunos avances aunque aún quedan muchas demandas sin atender. En el año 1984, la provincia de Formosa aprobó la Ley $\mathrm{N}^{\circ} 426 / 84$, en la que se reconocieron los derechos territoriales indígenas, y que luego originó un proceso de "transferencias de tierras en propiedad comunitaria". Según datos oficiales, la cifra total de tierras transferidas a los pueblos wichí, toba y pilagá ronda las 300.000 ha, con un promedio de 2.000 ha por comunidad pero que se encuentran poco interconectadas unas con otras. Esta situación conlleva a que los mariscadores deban atravesar propiedades privadas en busca de su alimento (Matarrese, 2019); es decir, contrariamente a lo estipulado en la constitución nacional y en la Ley $N^{\circ} 426 / 84$, no fueron restituidas las tierras necesarias para garantizar las actividades económicas mínimas, ni mucho menos las tierras que "tradicionalmente habitan".

Durante el último censo provincial se registraron unas 120 comunidades wichís y alrededor de 15.000 personas que en su mayoría hablan la lengua wichí. A pesar de que los wichís tienen nombres en su propia lengua tanto para las aldeas en las que viven como para los sitios que forman parte de su territorio tradicional, en la nomenclatura cartográfica oficial de Formosa existen menos de una decena de topónimos en wichí, y para la zona donde llevo a cabo mi trabajo, se registra un único nombre indígena, cuya ortografía no cuenta con la conformidad de los integrantes de la aldea que nombra: Los Pocitos-Tay'ú1.

Por todo esto, y en el contexto actual de homogeneización cultural, del avance de las industrias extractivas hidrocarburífera, maderera y agropecuaria sobre los bosques chaqueños y las tierras indígenas, los mapas se han convertido en territorios de disputa, a la vez que en herramientas útiles para disputar esos territorios. En este sentido, el mapeo participativo se ha utilizado como un instrumento tanto para salvaguardar las memorias colectivas de los pueblos aborígenes, como para demarcar y defender sus territorios ancestrales. En efecto, fueron muchas las experiencias en el continente americano, desde los reclamos de las First Nations en Canadá en la década de los 70 hasta los recientes reclamos de los wichi en Argentina, donde el mapeo participativo permitió a organizaciones indígenas y campesinas lograr importantes avances en sus demandas territoriales (Chapin et al., 2012; Palmer, 2005, pp. 3-5.; Salamanca, 2012; Sletto et al., 2013).

El objetivo de este artículo es presentar y discutir el conocimiento toponímico de los habitantes de dos aldeas wichís del Noroeste de Formosa, conocidas como Pescado Negro y Los Pocitos-Tay'ú ${ }^{2}$. Para cumplirlo, el artículo se plantea tres metas: (1) recopilar los nombres de los lugares, traducirlos, localizarlos en un mapa y contextualizarlos culturalmente; (2) exponer y analizar las explicaciones etimológicas que dan los propios actores para cada nombre y algunos procesos que siguen los topónimos; (3) comparar el repertorio toponímico analizado con otros repertorios de zonas aledañas. Esta contribución, pretende ser un aporte para la bibliografía toponímica, geográfica, lingüística y ecológica, y como finalidad última, contribuir a las reivindicaciones territoriales de los wichís de las aldeas estudiadas.

La gran mayoría de los habitantes de Pescado Negro y Los Pocitos-Tay'ú, se autoadscriben al gentilicio de "carmeños". Dicho gentilicio, proviene de la antigua Misión El Carmen, fundada en 1939 por los anglicanos de la Sociedad Misionera Sudamericana, como una subestación de la Misión El Yuto (SAMS, 1940 p. 35). Vale aclarar, que la mayoría de los colaboradores se

\footnotetext{
${ }^{1}$ La ortografía del topónimo aceptada por la propia comunidad, y que es coherente también con el "alfabeto wichí unificado" (Buliubasich et al., 2004), debiera ser To $Y^{\prime} O$, o si se quisiera mantener el nombre criollo Los Pocitos To $Y^{\prime} O$.

2 Ninguna de las dos aldeas posee datos censales oficiales, y aunque los hubiere, debido a la gran movilidad de sus habitantes los valores serían apenas aproximaciones. En el tiempo que duró la investigación, el número de habitantes de cada aldea rondó las 150 personas. Además, cada aldea posee 5.000 ha que fueron transferidas en el marco de la Ley $N^{\circ} 486 / 84$
} 
autoadscriben también a la parentela de los cigüeñas y el resto se reconocen como miembros de otras parentelas: antepasados del palo (halä-tetsel) y avispa carnicera (masa) ${ }^{3}$.

Los resultados que se presentan son fruto de un mapeo participativo, emanado en buena medida de las propias comunidades, pero coordinado y registrado por quien suscribe. Entre los años 2016 y 2019, el autor realizó cinco viajes a las aldeas mencionadas donde llevó a cabo reuniones individuales y grupales. Con esta información, se confeccionaron listas de topónimos y mapas provisorios que luego se revisaron, modificaron y volvieron a modificar, hasta llegar a una propuesta acordada, que dejó conforme a la mayoría de los participantes. Afortunadamente, se involucraron alrededor de 30 personas, no solo las que instaron inicialmente al autor a realizar el estudio.

La escritura de los topónimos en lengua wichí resultó ser una fuente de controversias. Era algo esperable, puesto que la lengua wichí presenta grandes variaciones dialectales y que, a pesar de existir un "alfabeto wichí unificado" (Buliubasich et al., 2004), todavía no existe un acuerdo real sobre la ortografía del wichí. De hecho, para este trabajo, el investigador resolvió en conjunto con las comunidades la elaboración de dos mapas: uno que conjugaba la propuesta del investigador y los deseos y exigencias de sus colaboradores ${ }^{4}$, y otro, que es el que aquí se presenta, que intenta adecuarse a una ortografía wichí todavía en construcción -pero que de a poco va imponiéndose-, que involucra al "alfabeto wichí unificado" (Buliubasich et al., 2004), a la Biblia en wichí traducida por los anglicanos (Biblia Wichí, 2002) y al diccionario del misionero anglicano Robert Lunt (2016). En este escrito utilizo el siguiente alfabeto: $\boldsymbol{a}, \ddot{\boldsymbol{a}}, \boldsymbol{e}, \ddot{\boldsymbol{e}}, \boldsymbol{i}$, o, o, $u, c h, c h h, c h^{\prime}, f w, h, j, k, k h, k^{\prime}, k w, k w^{\prime}, I, I^{\prime}$, $l h, m, m h, m^{\prime}, n, n h, n^{\prime}, p, p h, p^{\prime}, s, t, t h, t^{\prime}, t s, t s h$, $t s^{\prime}, w, w h, w^{\prime}, y, y h, y^{\prime}$.

Son necesarias dos últimas aclaraciones antes de continuar. La primera es que los nombres científicos de las especies que aparecen citadas no fueron recolectadas ni identificadas por el autor, sino que se obtuvo de la bibliografía específica sobre el tema (Arenas, 2003; Martínez Crovetto, 1995; Suárez, 2014), y particularmente de la contribución de Pastor Arenas, que se llevó a cabo en los mismos lugares donde se desarrolló esta investigación.

La segunda aclaración, es que la ubicación de la mayoría de los sitios no está georreferenciada. Esta falta se debe a dos motivos. En algunos casos, porque actualmente

\footnotetext{
3 Para ampliar sobre el complejo sistema de nombres de parentela wichís y los sistemas de organización social, sugiero consultar los estudios de Palmer (2005 pp. 118-133) y de Montani (2017 pp. 93100).

4 Se entregarán a las escuelas al menos tres mapas de grandes dimensiones, y otros de menor tamaño para las personas que se interesaron en poseer uno propio.
}

los sitios son inaccesibles: las grandes fluctuaciones estacionales del río, y en particular sus crecientes arrasadoras, modifican cada año el paisaje y borraron las vías de acceso o dejaron lugares totalmente sepultados. En otros casos, porque los alambrados de los nuevos campos privados, cuidados a veces "a punta de pistola", restringen en la actualidad el acceso a algunos sitios del antiguo territorio wichí. De todos modos, vale destacar que aún bajo estas circunstancias se lograron ubicar los lugares en el mapa, en general con un consenso elevado de parte de los participantes.

\section{Grandes tópicos}

En total se recogieron 133 topónimos para designar 119 lugares. Sin embargo, 13 de esos nombres son, probablemente, traducciones al idioma wichí del topónimo criollo; para el objetivo de este trabajo, no tiene sentido analizar sus nombres y narrativas, aunque luego serán retomados. En este apartado, se analizarán las historias y los significados de los 120 nombres que son propiamente wichís, que corresponden a 108 lugares (Tabla 1).

Se distribuyeron prácticamente todos los topónimos en el mapa (Figura 1), salvo 'Cardonal's, 'Conejitos' y 'Palosantal'. El motivo de la omisión de estos sitios, es que fueron mencionados únicamente por un anciano que no recuerda dónde estaban precisamente ubicados. Tampoco se ubicaron Fwilula, Tutnekwat ni Wumujmaj, debido a que no hubo un acuerdo entre los colaboradores sobre la ubicación de ninguno de ellos.

El siguiente análisis está basado en la idea de John Palmer (2005 pp. 41-77), según la cual la toponimia wichí expresa la teoría ecológica de este pueblo. Palmer sostiene que los wichís asignan nombres a los sitios del entorno que les resultan significativos desde un punto de vista cultural y que, por ello, la toponimia expresa más una "percepción cultural de la realidad" que una descripción minuciosa del paisaje. Según este autor, en esta percepción no existe una oposición taxativa entre la naturaleza y la cultura, sino que ambas están unidas en una contienda mayor, que se debate entre "la vida -que ambas aquí representan- y la muerte, el enemigo común" (Palmer, 2005 p. 74). De este modo, en la toponimia están documentados una mayoría de sitios con "connotaciones funestas", para ratificar así las ventajas que los wichís crean "en el punto cosmocéntrico del 'sitio de viviendas'" conformado por cada comunidad.

Entonces, aun cuando existan múltiples posibilidades de análisis y criterios para agrupar los nombres, quiero comenzar por destacar tres grandes temas que considero dominan la toponimia wichí: la fauna, la flora y el agua. La

\footnotetext{
${ }^{5}$ Los topónimos que son traducciones de la lengua wichí al castellano se distinguen por el entrecomillado simple. Para consultar el nombre en wichí se debe revisar la Tabla 1.
} 


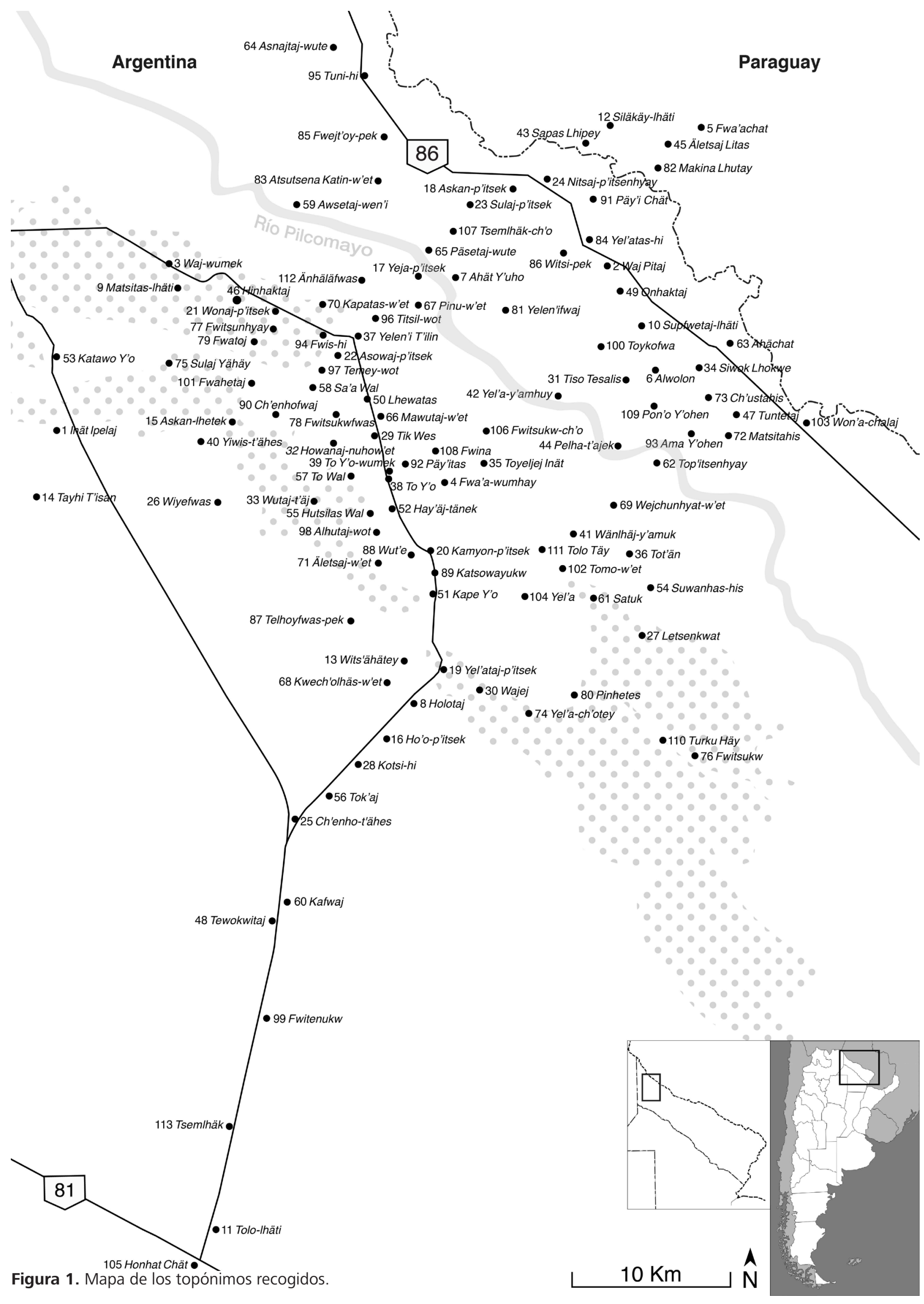

Figure 1. Map of the collected toponyms. 
fauna es nombrada en el $38 \%$ de los topónimos, la flora, en el $21 \%$, y la presencia de agua, en el $30 \%$.

Considerando que la zona es uno de los lugares más cálidos de Sudamérica y que tiene un periodo de sequía de casi seis meses (Iriondo, 2006), es comprensible que conocer la ubicación del agua en el territorio sea prioritario (cf. Palmer, 2005 p. 44). Igualmente comprensible, es que el $40 \%$ de los nombres refieran a animales y plantas que fueron o son considerados alimenticios. Así, en conjunto, alrededor del $70 \%$ de los nombres evocan los dispersos sitios con agua y alimento en medio del bosque semiárido. De ahí que pueda decirse que los topónimos conforman un mapa económico.

Otros estudios toponímicos chaqueños coinciden en la preponderancia de los nombres vinculados directa o indirectamente a la presencia de agua, aunque con algunas diferencias. Salvo por los registros de Montani y Juárez (2015), cuyos valores son similares a los obtenidos en esta investigación ${ }^{6}$, tanto los registros de Luis De la Cruz (1995) entre los tobas de Sombrero Negro, como los de Palmer (1995) entre los wichís occidentales, los de Ana Dell' Arciprete (1991) entre los pilagás y los de Pablo Wright (1991) entre los tobas de Misión Tacaaglé, los topónimos relacionados con el agua sobrepasan el $50 \%$ de los nombres de sus respectivo repertorios. La diferencia podría estar relacionada con que los recorridos de los carmeños siempre fueron cercanos al río y el acceso al agua es, por tanto, menos urgente.

Dejando casi en ridículo el ánimo clasificatorio del autor, nos encontramos con muchos topónimos que involucran dos y hasta tres de estas categorías. Sin embargo, seguiremos adelante con el análisis compartimentado, sabiéndolo exógeno a las concepciones wichí, pero intentando integrar las categorías para subsanar en parte la traición.

\section{Animales y plantas}

En los 120 topónimos que forman el repertorio estudiado, hay 45 menciones de 35 especies animales ${ }^{7}$. El grupo más representado es el de los mamíferos, con 14 especies; le siguen las aves, con nueve, los insectos, con siete, los reptiles, con tres, y hay por último un pez y un anélido. Es llamativa la escasa participación de los peces en el repertorio si se considera que el $77 \%$ de los animales nombrados son o fueron utilizados como recursos alimenticios (cf. Arenas, 2003) y que, como se explicó, los carmeños pasaban gran parte del año en las cercanías

\footnotetext{
${ }^{6}$ Montani y Juárez (2015) no realizaron conteos de su repertorio toponímico, sino que fueron realizados por mí siguiendo los mismos criterios que utilicé para este estudio (se dejaron afuera los topónimos wichís que son traducciones ad hoc de los topónimos criollos): de los 181 topónimos que analizaron, tomé 110 . Los resultados fueron: $36 \%$ zootopónimos, 23\% fitotopónimos y 21\% hidrotopónimos.

${ }^{7}$ Opté por contabilizar solo aquellos animales que también lo son para la biología académica. Es decir, que se dejaron afuera de la cuenta a los "animales" que tienen un carácter extraordinario incluso para los propios wichís: el "ukumar" (päsetaj) y el "viborón" (lëwo).
}

del río, pescando (la pesca, de hecho, es evocada en cuatro topónimos). Al mismo tiempo, tanto las especies de mamíferos y aves codiciadas por su carne, como las de insectos melíferos buscados por sus larvas y mieles, sí se encuentran bien representadas en la cartografía wichí.

En general, la importancia y el gran conocimiento del mundo animal también se evidencia en la variedad de informaciones sobre la ecología chaqueña y la fenología insinuada en los topónimos. Se destacan los distintos abrevaderos ('Bebedero del Gato Montés', 'Bebedero de la Avispa'), lugares de cruce de las aguas ('Cruzadero del Tatú Carreta'), refugios ('Morada del Pecarí', 'Morada del Aguará Guazú') y nidos ('Cueva del Pájaro Carpintero'), y los lugares que "contienen" líquidos y vida ('Recipiente de la Sanguijuela').

La presencia de animales agoreros es algo que los topónimos destacan, sobre todo si se trata de un ave de mal augurio, como en 'Nidos de Lechuzón Negruzco's. Igualmente importante son aquellos animales que presagian desgracias con un comportamiento inhabitual, como el ave mencionada en 'Montura de la Perdiz', puesto que "las perdices nunca se están trepadas a un palo", explicaron los wichí. Los topónimos también registran la salvajina de dimensiones o colores fuera de lo común ('Conejitos', 'Grandes Termiteros', 'Rana Roja'). Y, por supuesto, otros topónimos aluden a las especies peligrosas como el jaguareté, la lampalagua o el gato montés, y los parásitos molestos como la sanguijuela. Sin embargo, ni las especies peligrosas ni las molestas son percibidas negativamente por los wichís, por el contrario, son valoradas ya que la biodiversidad y abundancia de organismos son necesarias para el bienestar de la sociedad (Palmer, 2005 p. 53).

La muerte está igualmente presente en el mapa, y mayormente posee connotaciones negativas para los wichís. Se pueden encontrar cadáveres desperdigados por el territorio ('Cadáver de Caballo', 'Cadáveres de Pecari') o partes de cuerpos ('Cabeza del Biguá', 'Cuero de Cebú'). Las causas de muerte son desconocidas usualmente. Pero también hay casos en los que se conocen las causas, como un evento natural extraordinario o la mala praxis de un cazador. Un ejemplo de lo primero es el sitio 'Esqueletos de Vieja del Agua' que lleva ese nombre porque recuerda una creciente excepcional del Río Pilcomayo, que generó una gran mortandad de esos peces. Ejemplos de la mala praxis cinegética son los sitios 'Ratas Quemadas' o 'Tucuras Quemadas', que testimonian efectos colaterales indeseados de la caza mediante el fuego. En sentido contrario, el sitio 'Oso Hormiguero Trampeado' es más bien comentado con un tono humorístico, porque recuerda un evento en el que, en una trampa preparada para un ñandú, cayó un oso homiguero; este sería el caso

\footnotetext{
${ }^{8}$ La identificación de esta especie es conflictiva ya que las informaciones publicadas tomando como referencia el zoónimo wichí no se condicen con las descripciones de los wichís consultados.
} 
Tabla 1. En este índice toponímico se presentan los topónimos recopilados. El repertorio está organizado alfabéticamente según las traducciones de los topónimos wichís. Además, se consignan los topónimos wichí en su propia lengua, los topónimos criollos (cuando los hubiere) y las explicaciones que dieron los colaboradores para cada topónimo.

Table 1. In this index of toponyms, the collected place names are compiled. The list is organized alphabetically by the translations of the Wichi toponyms. In addition, Wichi place names are listed in their own language, as well as the Creole place names (when available) and the explanations given by contributors for each place name.

\begin{tabular}{|c|c|c|c|}
\hline Traducción & $\begin{array}{l}\text { Nº de mapa } \\
\text { Topónimo Wichí }\end{array}$ & $\begin{array}{l}\text { Topónimo } \\
\text { Criollo }\end{array}$ & Relatos \\
\hline Agua Blanca & 1 Inät Ipelaj & & \\
\hline (a) Agua Larga; (b) Cola Profunda & $\begin{array}{l}\text { (a) } 2 \text { Waj Pitaj; (b) } \\
\text { Chäs Pitoj }\end{array}$ & Buena Vista & $\begin{array}{l}\text { (a) En el lugar hay una cañada grande y profunda; (b) es una cañada que tiene una } \\
\text { forma similar a la de una cola animal. }\end{array}$ \\
\hline Agua Vieja & 3 Waj-wumek & El Quebracho & Es una aguada que nunca se seca. \\
\hline Algarroba Arruinada (Prosopis alba) & 4 Fwa'a-wumhay & & \\
\hline Algarrobal (Prosopis spp.) & 5 Fwa'achat & & \\
\hline Algodón (Gossypium sp.) & 6 Alwolon & El Algodón & Es la traducción del nombre criollo del lugar. \\
\hline Ánima Ardiente & 7 Ahät Y'uho & & En el sitio unos wichís vieron una gran llamarada producida por un ánima. \\
\hline Arenal & 8 Holotaj & & En el lugar hay un arenal. \\
\hline $\begin{array}{l}\text { Bebedero de las Avispas Bala Puka } \\
\text { (Polistes sp.) }\end{array}$ & 9 Matsitas-Ihäti & & Es una laguna donde abrevaban avispas "bala puka". \\
\hline $\begin{array}{l}\text { Bebedero de la Avispa (Plebeia } \\
\text { catamarcensis) }\end{array}$ & 10 Supfwetaj-Ihäti & & \\
\hline Bebedero de la Vaca & 11 Tolo-Ihäti & Corralito & Es la reinterpretación del nombre criollo del lugar. \\
\hline $\begin{array}{l}\text { Bebedero del Gato Montés } \\
\text { (Oncifelis geoffroyi) }\end{array}$ & 12 Siläkäy-Ihäti & & Es un abrevadero nocturno de un "gato montés". \\
\hline Benteveos (Pitangus sulphuratus) & 13 Wits'ähätey & $\begin{array}{l}\text { Cañada } \\
\text { Larga }\end{array}$ & Es una aguada donde se avistaron muchos benteveos. \\
\hline Bosque Desierto & 14 Tayhi T'isan & Monte Rico & Es una zona boscosa, poco habitada por humanos y con abundancia de animales. \\
\hline $\begin{array}{l}\text { Cabeza del Biguá (Phalacrocorax } \\
\text { olivaceus) }\end{array}$ & 15 Askan-Ihetek & Alambrado & $\begin{array}{l}\text { Es una aguada donde unos wichís cazaron un "biguá". Luego de comerlo, } \\
\text { colgaron su cabeza en un árbol. }\end{array}$ \\
\hline Cadáver de Gallo (Gallus gallus) & 16 Ho'o-p'itsek & & $\begin{array}{l}\text { Un wichí llamado Gallo, salió a cazar solo al monte y se encontró con una mujer } \\
\text { hermosa y rubia, que le dio un regalo y que él aceptó. Al volver a la aldea se } \\
\text { enfermó, y al día siguiente falleció. }\end{array}$ \\
\hline Cadáver de Yeja & 17 Yeja-p'itsek & & En el lugar fue encontrado el cadáver de una chamana Ilamada Yeja. \\
\hline $\begin{array}{l}\text { Cadáver del Biguá (Phalacrocorax } \\
\text { olivaceus) }\end{array}$ & 18 Askan-p'itsek & Pozo del Toro & Es una aguada donde unos wichís encontraron el cadáver de un "biguá". \\
\hline Cadáver del Caballo & 19 Yel'ataj-p'itsek & $\begin{array}{l}\text { Pozo de } \\
\text { Maza }\end{array}$ & En el lugar se encontró el cadáver de un caballo. \\
\hline Cadáver del Camión & 20 Kamyon-p'itsek & & $\begin{array}{l}\text { En el sitio un "viborón" hizo volcar a un camión. Por las noches suelen suceder } \\
\text { hechos similares a los transeúntes desprevenidos. }\end{array}$ \\
\hline Cadáver de Halcón (Falco sp.) & 21 Wonaj-p'itsek & & En el lugar se encontró el cadáver de una mujer Ilamada "Halcón". \\
\hline Cadáver del Nivaclé & 22 Asowaj-p'itsek & & $\begin{array}{l}\text { Wichís y nivaclés se aliaron y convivieron hasta que hubo desacuerdos que } \\
\text { llevaron a un enfrentamiento. En el lugar quedó el cadáver de un nivaclé. La } \\
\text { historia se relaciona con 'El Quemado' y 'Chiripa Rota'. }\end{array}$ \\
\hline $\begin{array}{l}\text { Cadáver del Oso Hormiguero } \\
\text { (Myrmecophaga tridactyla) }\end{array}$ & 23 Sulaj-p'itsek & & \\
\hline $\begin{array}{l}\text { (a) Cadáveres de Pecarí (Tayassu } \\
\text { pecari); (b) Morada del Pecarí }\end{array}$ & $\begin{array}{l}\text { (a) } 24 \text { Nitsaj- } \\
\text { p'itsenhyay; (b) } \\
\text { Nitsaj-w'et }\end{array}$ & $\begin{array}{l}\text { Misión El } \\
\text { Carmen }\end{array}$ & (a) En el sitio se encontraron muchos cadáveres de "pecari". \\
\hline $\begin{array}{l}\text { Caparazones de Quirquincho } \\
\text { (Tolypeutes matacus) }\end{array}$ & 25 Ch'enho-t'ähes & $\begin{array}{l}\text { Pozo } \\
\text { Sargento }\end{array}$ & En el lugar se encontraron muchos caparazones de "quirquincho". \\
\hline Chaguarcitos (Bromelia serra) & 26 Wiyefwas & & \\
\hline Chañaral (Geoffroea decorticans) & 27 Letsenkwat & Chañaral & Es la traducción del nombre criollo del lugar. \\
\hline Chiquero & 28 Kotsi-hi & & $\begin{array}{l}\text { En el lugar había un chiquero de un criollo que cuidaba mal a sus cerdos, que un } \\
\text { día se escaparon. }\end{array}$ \\
\hline Chiripa Rota & 29 Tik Wes & El León & $\begin{array}{l}\text { Wichís y nivaclés convivieron en la zona, hasta que se enfrentaron. Tras la victoria, } \\
\text { los wichís tomaron una niña de rehén, que luego fue violada y quedó } \\
\text { embarazada. La niña murió mientras paría. La historia se relaciona con 'Cadáver } \\
\text { del Nivaclé' y 'El Quemado'. }\end{array}$ \\
\hline Con Agua & 30 Wajej & Pelícano & En el lugar hay una aguada. \\
\hline Convite de las Viudas & 31 Tiso Tesalis & Palomita & $\begin{array}{l}\text { Un conflicto relacionado a los ingenios diezmó un grupo wichí, dejando viudas } \\
\text { con hijos. Varones solteros de otro grupo se "repartieron" esas viudas. La } \\
\text { "repartición" fue considerada un acto solidario, puesto que subsistir en aquellos } \\
\text { tiempos sin un grupo era muy difícil. }\end{array}$ \\
\hline $\begin{array}{l}\text { Cruzadero del Tatú Carreta } \\
\text { (Priodontes giganteus) }\end{array}$ & $\begin{array}{l}32 \text { Howanaj- } \\
\text { nuhow'et }\end{array}$ & & $\begin{array}{l}\text { Es un madrejón donde, una noche de luna llena, unos wichís vieron un "tatú } \\
\text { carreta" cruzando la aguada junto a sus crías. }\end{array}$ \\
\hline Cuero del Cebú & 33 Wutaj-t'äj & & En el lugar wichís encontraron el cuero de un "cebú" perdido. \\
\hline $\begin{array}{l}\text { Cueva del Pájaro Carpintero } \\
\text { (Campephilus leucopogon) }\end{array}$ & 34 Siwok Lhokwe & & \\
\hline $\begin{array}{l}\text { (a) El Cansado por el Agua; (b) } \\
\text { Morada de Vellos de la Vagina }\end{array}$ & $\begin{array}{l}\text { (a) } 35 \text { Toyeljej Inät; } \\
\text { (b) Sutsiley-w'et }\end{array}$ & Sunchal & $\begin{array}{l}\text { (a) Luego de una gran sequía, un chamán realizó un ritual para traer lluvia. Logró } \\
\text { su cometido pero quedó muy cansado. La historia se relaciona con 'Sentimiento } \\
\text { de frío'; (b) "Vellos de la Vagina" es el apodo de una criolla que residía en el lugar. }\end{array}$ \\
\hline El Llamado a los Gritos & 36 Tot'än $^{\prime}$ & & $\begin{array}{l}\text { En el lugar hay un bosque muy cerrado, donde es posible escuchar el llamado } \\
\text { desaforado de una persona desaparecida hace años. }\end{array}$ \\
\hline $\begin{array}{l}\text { El Pato (Callonetta leucophrys) } \\
\text { Nada }\end{array}$ & 37 Yelen'i T'ilin & El Caracol & Es una aguada donde había un pato nadando en zigzag. \\
\hline El Quemado & 38 To Y'o & Los Pocitos & $\begin{array}{l}\text { Wichís y nivaclés se aliaron, derrotaron a un grupo toba y tomaron a uno de ellos } \\
\text { de rehén, que luego quemaron allí mismo. La historia se relaciona con 'Chiripa } \\
\text { Rota' y 'Cadáver del Nivaclé'. }\end{array}$ \\
\hline El Quemado Viejo & 39 To Y'o-wumek & Los Pocitos & En el lugar fue abandonado un asentamiento llamado 'El Quemado'. \\
\hline $\begin{array}{l}\text { Esqueletos de Vieja del Agua } \\
\text { (Pterygoplichthys sp.) }\end{array}$ & 40 Yiwis-t'ähes & Campo Azul & $\begin{array}{l}\text { Es una aguada en donde se encontraron muchos esqueletos de "vieja del agua" } \\
\text { después de una gran creciente. }\end{array}$ \\
\hline $\begin{array}{l}\text { Excremento de Suri (Rhea } \\
\text { americana) }\end{array}$ & 41 Wänlhäj-y'amuk & Pichanal & \\
\hline $\begin{array}{l}\text { Excrementos de Tapir (Tapirus } \\
\text { terrestris) }\end{array}$ & 42 Yel'a-y'amhuy & & Es una aguada en cuyas orillas, wichís observaron mucho excremento de "tapir". \\
\hline Fragmentos de Sapas & 43 Sapas Lhipey & & $\begin{array}{l}\text { En el lugar wichís encontraron un pedazo de avión de combate (de la Guerra del } \\
\text { Chaco) colgando de un árbol. En él se podía leer la palabra "sapas". }\end{array}$ \\
\hline Golpeado por el Rayo & 44 Pelha-t'ajek & & En el lugar un rayo golpeó un árbol y lo destrozó, dejando un tocón quemado. \\
\hline Gran Cháguar (Deinacanthon & 45 Äletsaj Litas & & En el lugar se encontraron plantas de "cháguar" enormes. \\
\hline
\end{tabular}




\begin{tabular}{|c|c|c|c|}
\hline $\begin{array}{l}\text { Gran Molle (Sideroxylon } \\
\text { obtusifolium) }\end{array}$ & 46 Hinhaktaj & La Ceiba & En el sitio se destacaba un enorme molle, donde siempre había monos trepados. \\
\hline Gran Roca & 47 Tuntetaj & & $\begin{array}{l}\text { Es un lugar de difícil acceso, en el medio de un bosque cerrado. Hay un chaguaral } \\
\text { alto y en el centro de esta formación hay dos rocas, una menor que la otra, que } \\
\text { con el tiempo aumentaron de tamaño (en el Oeste formoseño prácticamente no } \\
\text { hay rocas, salvo que sean alóctonas). }\end{array}$ \\
\hline Gran Río & 48 Tewokwitaj & La Cañada & $\begin{array}{l}\text { Es una cañada que se formó tras una creciente extraordinaria del Pilcomayo. La } \\
\text { misma creciente se vincula con 'Esqueletos de Vieja del Agua'. }\end{array}$ \\
\hline $\begin{array}{l}\text { Gran Sacha Sandía (Sarcotoxicum } \\
\text { salicifolium) }\end{array}$ & 49 Onhaktaj & & En el lugar había un gran árbol de "sacha sandia". \\
\hline $\begin{array}{l}\text { Grandes Termiteros } \\
\text { (Constrictotermes cyphergaster) }\end{array}$ & 50 Lhewatas & Las Lagunas & En el sitio se encontraron termiteros muy grandes. \\
\hline Grasa Quemada & 51 Kape Y'o & El Tronquito & $\begin{array}{l}\text { Grasa es el nombre de un wichí que engañaba a su esposa con otra mujer. } \\
\text { Cuando la esposa lo descubrió le arrojó aqua hirviendo. }\end{array}$ \\
\hline $\begin{array}{l}\text { (a) Hígado del Jaguar (Panthera } \\
\text { onca); (b) Lagunitas }\end{array}$ & $\begin{array}{l}\text { (a) } 52 \text { Hay'äj-tänek; } \\
\text { (b) Lawunitas }\end{array}$ & & $\begin{array}{l}\text { (a) En el lugar un cazador mató un jaguareté y luego de sacarle su hígado, lo } \\
\text { colgó en un árbol; (b) es una aldea que fundaron wichís provenientes del sitio } \\
\text { llamado Lagunitas. }\end{array}$ \\
\hline $\begin{array}{l}\text { (a) Holgazán Quemado; (b) El Ánima } \\
\text { Golpea el Palo }\end{array}$ & $\begin{array}{l}\text { (a) } 53 \text { Katawo Y'O; } \\
\text { (b) Ahät Yaj Halä }\end{array}$ & El Divisadero & $\begin{array}{l}\text { (a) En el lugar fue quemado, a modo de castigo, un wichí que no colaboraba con } \\
\text { las tareas comunes; (b) una noche, unos wichís que estaban junto al fuego } \\
\text { escucharon el sonido del golpe de dos palos, cuando se acercaron no encontraron } \\
\text { a nadie. De allí se asume la acción de un ánima. }\end{array}$ \\
\hline Hormigueros (Formicidae) & 54 Suwanhas-his & Avispa & Es un lugar con una inusual cantidad de hormigueros. \\
\hline Hutsilas Copula & 55 Hutsilas Wal & & $\begin{array}{l}\text { Es una ciénaga donde fue visto un wichí llamado Hutsilas copulando con una } \\
\text { mujer. Luego encontraron sus cadáveres en las proximidades de la aguada. }\end{array}$ \\
\hline $\begin{array}{l}\text { (a) La Boca; (b) } 27 \text { de Julio; (c) } 28 \text { de } \\
\text { Noviembre }\end{array}$ & $\begin{array}{l}\text { (a) } 56 \text { Tok'aj; (b) } 27 \\
\text { de Julyu; (c) } 28 \text { de } \\
\text { Nowyemwle }\end{array}$ & & $\begin{array}{l}\text { (a) En el sitio había un obraje, y en ocasión de una visita del capataz, un grupo de } \\
\text { niños le arrojaron una piedra cuando este iba pasando en su caballo. La piedra le } \\
\text { dio en la boca, provocando la ira del capataz, que se bajó del caballo con su rifle } \\
\text { en mano y amenazó a los niños; (b) y (c) fueron dados por sus días de fundación. }\end{array}$ \\
\hline La Cópula & $57 \mathrm{To} \mathrm{Wal}$ & & \\
\hline La Mujer Hermosa Copula & $58 \mathrm{Sa}^{\prime} \mathrm{a}$ Wal & & $\begin{array}{l}\text { En el lugar unos wichís observaron copulando a una pareja de criollos. La mujer } \\
\text { era hermosa y de una posición social y económica alta. }\end{array}$ \\
\hline Laguna de los Tiestos & 59 Awsetaj-wen'i & & Es un madrejón donde wichís encontraron restos de alfarería de "los antiguos". \\
\hline $\begin{array}{l}\text { Lampalagua (Boa constrictor } \\
\text { occidentalis) }\end{array}$ & 60 Kafwaj & & \\
\hline $\begin{array}{l}\text { Lecherón (Sapium } \\
\text { haematospermum) }\end{array}$ & 61 Satuk & Lecherón & Es la traducción del nombre criollo del lugar. \\
\hline Los Cadáveres & 62 Top'itsenhyay & & \\
\hline Mistolar (Sarcomphalus mistol) & 63 Ahächat & & Es un lugar con una agrupación de "mistoles". \\
\hline $\begin{array}{l}\text { Montura de la Perdiz (Eudromia } \\
\text { formosa) }\end{array}$ & 64 Asnajtaj-wute & & $\begin{array}{l}\text { En el lugar un cazador wichí se encontró a una "perdíz" montada sobre la rama } \\
\text { de un árbol. Esto es considerado un mal presagio. }\end{array}$ \\
\hline Montura del Barbudo (el ukumar) & 65 Päsetaj-wute & & $\begin{array}{l}\text { En el sitio un grupo de wichís se encontró con un "ukumar" trepado a un árbol, y } \\
\text { uno de ellos le disparó un flechazo. El "ukumar", herido, juntó su propia sangre y } \\
\text { se las arrojó a los atacantes, quienes murieron en el acto. }\end{array}$ \\
\hline $\begin{array}{l}\text { Morada de Aguará Guazú } \\
\text { (Chrysocyon brachyurus) }\end{array}$ & 66 Mawutaj-w'et & & $\begin{array}{l}\text { 1) Un varón que volvía de mariscar, escuchó un sonido similar al aullido de un } \\
\text { "aguará guazú". Seguidamente, intentó hacer arrancar su motocicleta pero falló, } \\
\text { y no arrancó hasta que se alejó del sitio. 2) Aguará Guazú es el apodo de un } \\
\text { criollo. }\end{array}$ \\
\hline $\begin{array}{l}\text { Morada de Avispa Yana } \\
\text { (Scaptotrigona jujuyensis) }\end{array}$ & 67 Pinu-w'et & Lomada & $\begin{array}{l}\text { En el sitio vivía un criollo apodado Avispa Yana que solía comprar cuero de } \\
\text { animales. }\end{array}$ \\
\hline Morada de Manito & $\begin{array}{l}68 \text { Kwech'olhäs- } \\
\text { w'et }\end{array}$ & $\begin{array}{l}\text { Pozo de } \\
\text { Toledo }\end{array}$ & Es el sitio de residencia de un criollo que apodaban Manito. \\
\hline Morada de Trasero Pesado & $\begin{array}{l}69 \text { Wejchunhyat- } \\
\text { w'et }\end{array}$ & La Rinconada & En el lugar vive una criolla de apodo Trasero Pesado. \\
\hline Morada del Capataz & 70 Kapatas-w'et & & Era el lugar de residencia del capataz de un obraje cercano. \\
\hline $\begin{array}{l}\text { Morada del Cháguar (Deinacanthon } \\
\text { urbanianum) }\end{array}$ & 71 Äletsaj-w'et & & \\
\hline $\begin{array}{l}\text { Nidos de Avispa Bala Puka (Polistes } \\
\text { sp.) }\end{array}$ & 72 Matsitahis & & \\
\hline $\begin{array}{l}\text { Nidos del Lechuzón Negruzco (Asio } \\
\text { stygius) }\end{array}$ & 73 Ch'ustahis & & $\begin{array}{l}\text { En el lugar hay varios nidos de "lechuzón negruzco". Para los wichís, cuando el } \\
\text { ave emite un sonido como de "chasquido de huesos" augura malos presagios. }\end{array}$ \\
\hline Orejas de Tapir (Tapirus terrestris) & 74 Yel'a-ch'otey & Espinillo & $\begin{array}{l}\text { Es una aguada con gran cantidad de la planta acuática "orejas de tapir". El } \\
\text { fitónimo es por el parecido de la hoja con la oreja del tapir. }\end{array}$ \\
\hline $\begin{array}{l}\text { Oso Hormiguero Trampeado } \\
\text { (Myrmecophaga tridactyla) }\end{array}$ & 75 Sulaj Yähäy & El Oscuro & $\begin{array}{l}\text { En la orilla de una laguna un cazador puso una trampa de piola para cazar un suri. } \\
\text { Sin embargo, cuando volvió al día siguiente, encontró trampeado un oso } \\
\text { hormiguero. }\end{array}$ \\
\hline Palma (Copernicia alba) & 76 Fwitsukw & Palma Sola & Es la traducción del nombre criollo del lugar. \\
\hline Palmar (Copernicia alba) & 77 Fwitsunhyay & & \\
\hline Palmitas (Copernicia alba) & 78 Fwitsukwfwas & & En el lugar había palmas muy pequeñas a pesar de su longevidad. \\
\hline Palo Flojo (Albizia inundata) & 79 Fwatoj & & En el lugar hay una ciénaga y muchos árboles de "palo flojo". \\
\hline Pastos Altos (spp.) & 80 Pinhetes & Simbolar & Es un pastizal donde se solía ir a cazar. \\
\hline Patito (Callonetta leucophrys) & 81 Yelen'ifwaj & Patillo & Es la traducción del nombre criollo del lugar. \\
\hline Pedazos de Máquina & 82 Makina Lhutay & & En el lugar unos wichís encontraron pedazos de una máquina que desconocían. \\
\hline Pista de Baile de Atsutsena & $\begin{array}{l}83 \text { Atsutsena Katin- } \\
\text { w'et }\end{array}$ & & Atsutsena es el nombre de una wichí que dirigía el baile "sapo" en ese lugar. \\
\hline $\begin{array}{l}\text { (a) Potrero; (b) Misión El Carmen } \\
\text { Viejo }\end{array}$ & $\begin{array}{l}\text { (a) } 84 \text { Yel'atas-hi; (b) } \\
\text { Misyon El Kalmen- } \\
\text { wumek }\end{array}$ & & $\begin{array}{l}\text { (a) En el lugar había un potrero; (b) fue el primer asentamiento de la Misión El } \\
\text { Carmen. }\end{array}$ \\
\hline Pozo de Dedo Mocho & 85 Fwejt'oy-pek & & $\begin{array}{l}\text { Es el pozo de agua de un criollo que apodaban Dedo Mocho. El criollo compraba } \\
\text { cuero de animales. }\end{array}$ \\
\hline Pozo de la Masturbación & 86 Witsi-pek & El Remanso & Es una aguada donde vieron un joven masturbándose mientras se bañaba. \\
\hline Pozo de Ojitos & 87 Telhoyfwas-pek & & Es el pozo de agua de un criollo que apodaban Ojitos. \\
\hline Pozo Redondo/Derrumbe & 88 Wut'e & & En el lugar hay una aguada redonda. \\
\hline Quimil (Opuntia quimilo) & 89 Katsowayukw & El Quimil & Es la traducción del nombre criollo del lugar. \\
\hline Quirquinchito (Tolypeutes matacus) & 90 Ch'enhofwaj & & Es una aguada donde encontraron a un quirquincho adulto pero muy pequeño. \\
\hline
\end{tabular}




\begin{tabular}{|c|c|c|c|}
\hline $\begin{array}{l}\text { Rana (Leptodactylus chaquensis) } \\
\text { Roja }\end{array}$ & 91 Päy'i Chät & & Es una aguada donde se encontraron a una llamativa rana roja. \\
\hline $\begin{array}{l}\text { Ranas Grandes (Leptodactylus } \\
\text { chaquensis) }\end{array}$ & 92 Päy'itas & & En el lugar se encontraron ranas inusualmente grandes. \\
\hline $\begin{array}{l}\text { Ratones Quemados (Cricétido } \\
\text { pequeño) }\end{array}$ & 93 Ama Y'ohen & & $\begin{array}{l}\text { Era un pastizal donde, tras aplicar la técnica de caza del círculo de fuego, se } \\
\text { encontraron muchos ratones quemados. La técnica era muy utilizada en } \\
\text { pastizales. }\end{array}$ \\
\hline $\begin{array}{l}\text { (a) Recipiente de la Sanguijuela } \\
\text { (Hirudo sp.); (b) Pescado Negro }\end{array}$ & $\begin{array}{l}\text { (a) } 94 \text { Fwis-hi; (b) } \\
\text { W'ahat-chalaj }\end{array}$ & $\begin{array}{l}\text { Pescado } \\
\text { Negro }\end{array}$ & $\begin{array}{l}\text { (a) Es una aguada con una gran cantidad de ese hirudineo; (b) es la traducción del } \\
\text { nombre criollo del lugar. }\end{array}$ \\
\hline $\begin{array}{l}\text { Recipiente de la Tuna (Opuntia } \\
\text { ficus-indica) }\end{array}$ & 95 Tuni-hi & $\begin{array}{l}\text { Puerto } \\
\text { Yrigoyen }\end{array}$ & Es un lugar con muchas plantas de "tuna". \\
\hline Red de Grillo (Gryllus sp.) & 96 Titsil-wot & & $\begin{array}{l}\text { Grillo era el nombre de un perro que fue visto "pescando" en una aguada, } \\
\text { aprovechando que había poca agua. Lo mencionan con ironía, como una } \\
\text { simulación de la tradicional pesca con red. }\end{array}$ \\
\hline $\begin{array}{l}\text { (a) Red de Temey; (b) Nuestra Red; } \\
\text { (c) Perro; (d) Lagunitas Viejo }\end{array}$ & $\begin{array}{l}\text { (a) } 97 \text { Temey-wot; } \\
\text { (b) Lha-wot; (c) } \\
\text { Asinäj; (d) } \\
\text { Lawunitas-wumek }\end{array}$ & $\begin{array}{l}\text { Vuelta al } \\
\text { Perro }\end{array}$ & $\begin{array}{l}\text { (a) Es una laguna donde solía pescar el antiguo cacique Temey; (b) es un buen sitio } \\
\text { de pesca; (c) es la reinterpretación del nombre criollo del lugar; (d) allí había un } \\
\text { asentamiento llamado Lagunitas, que luego fue abandonado. }\end{array}$ \\
\hline Red del Yacaré (Caiman sp.) & 98 Alhutaj-wot & & $\begin{array}{l}\text { Es una aguada donde "pescaba" un yacaré. Es mencionado } \\
\text { irónicamente, como si pescara con una red al estilo wichí. }\end{array}$ \\
\hline Sacha Pera (Acanthosyris falcata) & 99 Fwitenukw & & \\
\hline $\begin{array}{l}\text { (a) Sentimiento de Frío; (b) El Ánima } \\
\text { Siente Frío }\end{array}$ & $\begin{array}{l}\text { (a) } 100 \text { Toykofwa; } \\
\text { (b) Ahät Yakofwa }\end{array}$ & & $\begin{array}{l}\text { (a) y (b) Luego de que un chamán invocara la lluvia, intentó volver a su hogar pero } \\
\text { por el agotamiento paró a descansar y se durmió. Lo rescataron antes de morir de } \\
\text { frío. La historia se relaciona con 'Cansado por el Agua'. }\end{array}$ \\
\hline Simbol (Cenchrus pilcomayensis) & 101 Fwahetaj & & Era un pastizal con abundancia de "simbol", donde se acostumbraba ir a cazar. \\
\hline Sitio de Descanso & 102 Tomo-w'et & & Era un sitio de paso, no para quedarse prolongadamente. \\
\hline Sombrero Negro & 103 Won'a-chalaj & $\begin{array}{l}\text { Sombrero } \\
\text { Negro }\end{array}$ & Es la traducción del nombre criollo del lugar. \\
\hline Tapir (Tapirus terrestris) & $104 \mathrm{Yel}^{\prime} a$ & Anta & Es la traducción del nombre criollo del lugar. \\
\hline Tierra Roja & 105 Honhat Chät & $\begin{array}{l}\text { Ingeniero } \\
\text { Juárez }\end{array}$ & $\begin{array}{l}\text { Es una zona cercana a una aguada con arcilla roja, muy utilizada en la alfarería } \\
\text { wichí. }\end{array}$ \\
\hline Tocón de la Palma (Copernicia alba) & 106 Fwitsukw-ch'o & & En el sitio hay un tocón de "palma". \\
\hline Tocón del Yuchán (Ceiba chodatii) & 107 Tsemlhäk-ch'o & & $\begin{array}{l}\text { En el lugar hay un gran "yuchán" que acumula agua en su tronco, y que puede } \\
\text { ser bebida en caso de necesidad. }\end{array}$ \\
\hline Totora (Typha domingensis) & 108 Fwina & & \\
\hline Tucuras (Acrididae) Quemadas & $109 P^{\prime}$ ohno Y'ohen & & $\begin{array}{l}\text { Era un pastizal donde luego de aplicar la técnica de caza del círculo de fuego, se } \\
\text { encontraron muchas "tucuras" quemadas. }\end{array}$ \\
\hline Turco Cavando & 110 Turku Häy & El Cavado & Es la reinterpretación del nombre criollo del lugar. \\
\hline Vaca Perdida & 111 Tolo Täy & Vaca Perdida & Es la traducción del nombre criollo del lugar. \\
\hline Vizcachitas (Lagostomus maximus) & 112 Änhäläfwas & & En el sitio había muchas "vizcachas" adultas pero pequeñas. \\
\hline $\begin{array}{l}\text { (a) Yuchán (Ceiba chodatii); (b) El } \\
\text { Cadáver }\end{array}$ & $\begin{array}{l}\text { (a) } 113 \text { Tsemlhäk; (b) } \\
\text { Top'itsek }\end{array}$ & & $\begin{array}{l}\text { (a) En el lugar había un gran "yuchán" solitario; (b) un wichí de la parentela } \\
\text { antepasados del palo, mató a otro de los avispa carnicera. Estos últimos en } \\
\text { venganza, mataron un familiar del asesino en el sitio 'Yuchán'. }\end{array}$ \\
\hline
\end{tabular}

de una muerte beneficiosa.

Por su parte, la vegetación aparece aludida en 25 topónimos que refieren a 19 especies, que pertenecen a 14 familias de plantas 9 . El $63 \%$ de estas especies son o fueron consideradas por los wichís como alimento (cf. Arenas, 2003).

Se encuentran topónimos que evocan grandes agrupaciones monoespecíficas ('Algarrobal', 'Mistolar', 'Palosantal') y otros que aluden a un único ejemplar solitario, pero que destaca en el paisaje ('Yuchán', 'Gran Molle'). La motivación de estos nombres reside en que muchos ejemplares de una misma especie pueden proveer abundante alimento, madera o medicina, o en que un gran árbol puede ser un buen lugar de descanso, al resguardo del sol, o incluso un reservorio de agua -el yuchán, con sus huecos, es famoso en este sentido (Arenas, 2003: 246-247; Suárez, 2014 p. 207).

Cuando los wichís practicaban el nomadismo, una técnica de caza muy utilizada consistía en encerrar a los animales que estaban en los pastizales en un círculo de fuego (Arenas, 2003 pp. 372-373). Lugares como 'Simbol' o 'Pastos Altos' hacen referencia a lugares aptos para tal técnica. Asimismo, los nombres 'Gran Cháguar' y

\footnotetext{
${ }^{9}$ Arecaceae, Bromeliaceae, Cactaceae, Capparaceae, Cervantesiaceae, Fabaceae, Malvaceae, Poaceae, Polygonaceae, Rhamnaceae, Sapotaceae, Solanaceae, Typhaceae, Zygophyllaceae.
}

'Morada del Cháguar' podrían estar relacionados con el rol fundamental de estas plantas en la industria textil wichí (Arenas, 1997; Montani, 2007 pp. 422-456).

El conocimiento wichí de los ciclos vitales expresado en los topónimos, destaca ciertas similitudes ecológicas que existen entre todos los organismos vivos. Como los animales (humanos o no), las plantas poseen sitios estables de asentamiento ('Morada del Cháguar', 'Recipiente de la Tuna'), pueden crecer y desarrollarse por fuera de la media ('Chaguarcitos', 'Gran Sacha Sandía', 'Palmitas'), y envejecen y mueren dejando restos en el paisaje ('Algarroba Arruinada', 'Golpeado por el Rayo', 'Tocón de Palma'). En estas analogías subyace la concepción wichí que ubica a todos los seres vivos en un mismo posicionamiento frente a la disputa entre los principios universales de la vida y la muerte (cf. Palmer, 2005 p. 53).

En el sitio 'Orejas de Tapir', ocurre una conjunción de elementos que ejemplifica la compleja trama de relaciones ecológicas e interdependencias presentes en la construcción toponímica. Por un lado, el nombre no se refiere literalmente a un tapir, sino que es el nombre de una planta cuyas hojas se parecen considerablemente a las orejas de ese animal. Por el otro, aunque no me fue posible identificar la planta, varios colaboradores comentaron que es acuática, por lo que el nombre señala, indirectamente, la presencia de agua. Es decir, una planta acuática es nombrada por características análogas a las de 
un animal10, muy codiciado por su carne, y a su vez está indicando que en el sitio hay agua, hecho fundamental para la supervivencia de la planta, del animal y de los wichís.

\section{Agua}

En la toponimia hay 37 referencias al agua, de las cuales 14 aparecen literalmente en el topónimo y otras 23 se infieren por las narrativas que los explican. De las 14 alusiones literales, tan solo una es de un curso de agua ('Gran Río'), mientras que las restantes son de aguas quietas. Que haya una sola referencia al río podría deberse a que, aun cuando el Pilcomayo es extremadamente meandroso y cambiante, por el tamaño e importancia del cauce su ubicación es siempre conocida. De hecho, el nombre 'Gran Río' recuerda una creciente extraordinaria que dejó huellas por doquier (los criollos llaman a este lugar La Cañada, por la gran erosión hídrica tras la creciente). Las aguas estancas son nombradas directamente como "agua" (waj o inät), "laguna" (wen'i), "pozo" (-pek) o "pozo redondo" (wut'e).

Los pozos (-pek) son siempre propiedad de una comunidad ('Pozo de la Masturbación') o de alguna persona ('Pozo de Ojitos'). "Pozos redondos" es un modo local de llamar a un tipo de hondonada del suelo que es producto de la acción erosiva de los ríos y la materia orgánica que arrastran, mientras que desde el punto de vista wichí, es un lugar producido por la furia de algún "viborón" (cf., p. ej., Montani y Juárez 2016 p. 143). Aun cuando estos seres habiten en el agua en general, los "pozos redondos" son uno de sus refugios preferidos. Por tal motivo, en las inmediaciones del sitio suelen acontecer hechos extraordinarios como apariciones de animales amenazantes que luego desaparecen, o motores de vehículos que fallan y hasta accidentes de personas desprevenidas. Aquí, una vez más, queda evidenciado cómo los elementos del entorno, incluso los inorgánicos, son nombrados en función de los vínculos que establecen con otros elementos.

En el Chaco Semiárido, conocer la ubicación de las aguas escondidas en el bosque tiene importancia al menos por dos motivos: porque permite saciar la sed o proveer agua para un sitio de viviendas; y porque, durante la época de sequía, en estos lugares las aguas bajan a punto tal que se vuelve muy fácil atrapar peces. El sitio 'Red de Grillo' hace referencia, con ironía, a este tipo de pesca: en una ocasión los wichís vieron a un perro, que apodaban "Grillo", "pescar" en esa aguada como si tuviese una red"1.

\footnotetext{
10 Suárez (2014 p. 405) encontró que muchos fitónimos wichí se nombran por sus vínculos con el mundo animal, entre ellos, las semejanzas morfológicas entre una parte de una planta y una parte de un animal, tal como aquí se describió.

${ }^{11}$ Montani (2017 pp. 312-317) plantea que el término -wot se puede utilizar como un genérico de red de pesca, pero también se aplica específicamente en dos casos: para las redes de pesca de inmersión y para las redes utilizadas en las cañadas. Este último uso, es el que se sugiere en la narrativa del topónimo 'Red de Grillo'. Asimismo, en otros topónimos, como 'Red del Yacaré' o 'Red de Temey', las historias de los nombres aluden a la red de inmersión.
}

Los topónimos que indican la presencia de agua indirectamente, lo hacen evocando los vínculos ecológicos del agua con los organismos vivos que dependen de ella. 'Tocón de Yuchán' resalta el gran tronco de uno de esos árboles, que siempre acumulaba agua y servía como reserva para humanos y otros animales. Las plantas y animales de hábitos acuáticos indican indirectamente la presencia de agua ('El Pato Nada', 'Totora'), al igual que los nombres que aluden a la pesca ('Red del Yacaré', 'Red de Temey') y, los ya mencionados, abrevaderos y "cruzaderos" de animales. La percepción del paisaje narrada en los topónimos da cuenta de una mirada ecológica centrada en lo relacional y no en la descripción de elementos aislados.

\section{La dinámica de los topónimos}

Con muchas traducciones surgieron complicaciones, ya sea porque los propios wichís desconocían su significado y/o porque no se podían corroborar con los diccionarios consultados (Claesson, 2008; Lunt, 2016; Montani com. pers.). Se podría hipotetizar que las dificultades de traducción son además el resultado de: 1) el nombre es antiguo y fue sufriendo pequeñas modificaciones durante su transmisión a lo largo del tiempo (por erosión fonológica) hasta llegar a un punto de ininteligibilidad; 2) el nombre es antiguo y utiliza un término que ha caído en desuso (por ser un arcaísmo o por tratarse de un nombre propio); 3) el nombre fue otorgado por un grupo con una lengua o variedad dialectal distinta.

Como regla general, cada topónimo tiene un significado comprensible para los hablantes, designa un lugar específico del territorio y tiene una historia que le dio origen y lo explica. Sin embargo, ya mencioné tres lugares de los que solo se conoce el nombre (Wumujmaj, Tutnekwat y Fwilula), y hay otros 27 que no tienen una historia que los explique (por ej. 'Lampalagua', 'Totora', 'Sitio de Descanso'). En función de estas observaciones, pareciera que los topónimos siguen un proceso que se inicia cuando un lugar es nombrado, y que finaliza cuando es olvidado por completo. Entre ambos extremos se pueden encontrar puntos intermedios. Toda esta sucesión de estados puede llevar a la superposición y convivencia de nombres de un mismo lugar, y así formar capas o estratos de topónimos.

En este proceso gradual hacia el olvido, encontramos que los topónimos de los carmeños podrían distribuirse entre los siguientes estados: 1) el nombre, su significado, la ubicación y el motivo son bien conocidos ('El Quemado', 27 de Julio); 2) el nombre, su significado y la ubicación son conocidos, pero los motivos se olvidaron por completo o se sugieren interpretaciones a partir del significado del nombre ('Algarroba Arruinada', 'Cueva del Pájaro Carpintero'); 3) el nombre es conocido, pero su localización se hace confusa, el significado y el motivo del nombre son desconocidos (Wumujmaj, Tutnekwat); 
4) solo se recuerda el nombre de un lugar, del que se desconocen su ubicación, significado y motivos de origen (Fwilula).

Además de estos estados, quizás más representativos, hay otros más sutiles que se parecieran vislumbrar cuando alguna de las variables mencionadas (ubicación, significado y motivo) se distribuye en rangos etarios específicos. Cuando la variable es conocida exclusivamente por los más ancianos, la podríamos considerar como propia de un nombre antiguo y que está más avanzado en el "proceso de olvido"; mientras que las conocidas específicamente por jóvenes y adultos, suelen ser de menor antigüedad y estar menos avanzadas en ese proceso. De todos modos, reflexionando sobre la participación y los aportes de los colaboradores, fue evidente que los ancianos son los que conocen mejor la toponimia, y los jóvenes suelen conocer únicamente los sitios que recorren para mariscar y las aldeas cercanas.

La inmensa mayoría de los topónimos estudiados (el 78\%) tiene una narración asociada. Esto es un fuerte indicio de la vitalidad del sistema toponímico y de cómo la práctica de dar nombres al espacio mantiene cierta vigencia, adaptándose a los tiempos que corren.

En consonancia con esta constante readecuación del mapa toponímico a la dinámica cultural, existe una manera "novedosa" de nombrar lugares que estuvieron habitados y luego fueron abandonados, mediante el uso del sustantivo -wumek, "descartado", "viejo". Al parecer es una metodología relativamente nueva, ya que solo se encontró aplicado a los lugares que fueron asentamientos estables, y esto en la historia wichí local comenzó hace alrededor de 80 años. En estos casos, el lugar abandonado cambia su nombre original por uno nuevo que consiste en el "nombre original"-wumek. Por su parte, el nombre original del lugar se traslada junto con las personas a una nueva locación. Vale aclarar que con esto no se quiere decir que todos los topónimos que lleven el término "viejo" tengan relación con esta lógica de nombrar. Veamos los casos en los que sí la tiene.

En 'El Quemado Viejo', el motivo de la mudanza fue una gran inundación que arrasó con la mitad de la aldea. La gente trasladó el asentamiento apenas a unos 400 $\mathrm{m}$ hacia el Sur, el sitio en ruinas fue rebautizado con el agregado de -wumek, y el lugar del nuevo asentamiento se nombró 'El Quemado'. Otro caso similar es el de 'Lagunitas Viejo'. Luego de una pelea entre dos hermanos una parte del grupo se mudó a una laguna llamada 'Red de Temey', donde fundaron un barrio que nombraron en español, Lagunitas. Con el tiempo la pelea se intensificó, y la gente de Lagunitas decidió mudarse a 'Hígado de Tigre', sitio al que rebautizaron como Lagunitas. Por último, en el sitio 'Misión El Carmen Viejo' se fundó por primera vez la Misión El Carmen, pero tras sucesivas inundaciones del río Pilcomayo, decidieron la mudanza definitiva a un nuevo destino, donde se fundó por segunda vez Misión El Carmen. En definitiva, los asentamientos sedentarios que luego fueron abandonados aparecen representados en la toponimia con una marca distintiva, y como un modo de registro propio de la historia de los poblamientos.

En la toponimia carmeña no hay dos lugares que tengan el mismo nombre. Esto se debe, en parte, a que los nombres funcionan como hitos singulares de un mapa destinado a minimizar el riesgo. Pues como señala Palmer (2005: 41), cuando una persona sale a mariscar le avisa a sus familiares a dónde se dirige utilizando un topónimo. Si algo llegara a sucederle, los allegados sabrán por dónde comenzar a buscar. Sin embargo, en otros repertorios toponímicos wichís, como los relevados por Palmer (1995) o por Montani y Juárez (2015), se encuentran algunos pocos nombres repetidos. Este hecho podría deberse a que esos trabajos conjugan el conocimiento toponímico de distintas aldeas, con historias complejas, sobre zonas muy amplias, mientras que el presente estudio se realizó con un grupo relativamente reducido que comparte una historia reciente marcada por la Misión El Carmen.

Por otro lado, hay 11 lugares que tienen más de un topónimo wichí, algo que parece contradecir lo que se dijo anteriormente. Sin embargo, en los hechos tal contradicción no existe, pues estos topónimos forman parte de distintos estratos toponímicos que de algún modo conviven. Es decir, la superposición de nombres sobre un mismo lugar resulta de la vigencia de la práctica toponímica, que implica nombrar nuevos espacios o renombrarlos cuando un viejo nombre se vuelve obsoleto o un nuevo nombre resulta más significativo. Veamos algunos ejemplos.

Los dos emplazamientos de la Misión El Carmen, ya contaban con nombres en lengua wichí: 'Potrero', la primera locación, y 'Cadáveres de Pecarí' o 'Morada del Pecarí', la segunda. Los nombres wichís solo fueron mencionados por los colaboradores más ancianos, mientras que los jóvenes solo escucharon hablar de Misión El Carmen y ninguno llegó ni siquiera a conocer el sitio porque el río borró todo rastro de ocupación. Este sería el caso de lugares que ya no se pueden visitar, pero que por la importancia socio-histórica aún son recordados.

Volviendo al lugar de la segunda instalación de la misión, vemos que tiene dos nombres. Estos topónimos empiezan a confundirse en la memoria de los ancianos. Es presumible que los nombres antiguos, que perdieron buena parte de su utilidad (geográfica y económica, y en parte también la histórica), prontamente caigan en el olvido.

Distinta es la situación de otros lugares con doble denominación que mantienen plena vigencia, como es el sitio llamado 'Yuchán' o 'El Cadáver'. En este caso, los nombres son utilizados, respectivamente, por 
dos parentelas wichís que circulaban por ese lugar: antepasados del palo y avispa carnicera. Ambos nombres están muy difundidos y son conocidos por todos, sin embargo 'El Cadáver' es más nuevo que 'Yuchán', e incluso el árbol que dio origen a este último nombre ya no existe, por lo que sería esperable que prevalezca el primero.

\section{La temporalidad en el paisaje toponímico}

Como se adelantó, en la toponimia existen marcas e indicios que permiten identificar estratos temporales. Muchos nombres describen prácticas sociales e incluso aspectos morales antiguos, que resultan anacrónicos para las generaciones actuales. Es decir, en el repertorio toponímico no solo hay elementos lingüísticos sincrónicos con un estado actual de la lengua hablada, sino que también presenta elementos diacrónicos (Trapero, 1995). De allí que el repertorio toponímico sea tanto un mapa ecológico, social y cultural contemporáneo como un reservorio de arcaísmos lingüísticos, de relictos ecológicos y culturales, etc.

El sitio 'Holgazán Quemado' evoca una práctica punitiva - la amenaza a una persona no colaborativa- que revela, a su vez, una postura moral -el valor fundamental de la cooperación en los tiempos en los que el nomadismo era condición para la supervivencia del grupo. Sin embargo, desde que se establecieron las iglesias cristianas entre los wichís y se produjo la "sedentarización", la sola idea de matar a alguien resulta escandalosa.

Otro ejemplo es 'Tierra Roja'. Un topónimo de gran importancia para la alfarería wichí porque permite ubicar un sitio con buena arcilla (cf. Arenas, 2003 pp. 227-229; Montani, 2017 pp. 247-259). En la actualidad, la alfarería solo se practica comercialmente, y las alfareras son muy pocas. En el mismo sentido, 'Laguna de los Tiestos', es un lugar con elementos que hasta les resultan anacrónicos a los más ancianos, ya que allí fueron encontrados restos de alfarería muy antiguos. Es decir, la toponimia carmeña también registra los "sitios arqueológicos", por así decirlo, que se reconocen como parte de una historia grupal más antigua.

Hay otros topónimos que evocan prácticas y elementos de la modernidad. 'Cadáver del Camión' y 'Pedazos de Máquina' ya dan cuenta de la presencia en el territorio de los objetos tecnológicos de los blancos (suwela), y hasta de las palabras prestadas del léxico castellano al wichí, como "kamyon" y "makina". El caso del camión es más complejo aún, ya que el nombre se explica por la interacción del vehículo con el "viborón": en un encuentro fortuito, un habitante antiguo del bosque se enfrenta a una máquina moderna, y la asesina, dejando el cadáver derribado del "gigante" como muestra de su poderío.

Eventos históricos como la Guerra del Chaco tampoco pasaron desapercibidos para los wichís. Se trató de una guerra entre dos países que involucró, además, a los pueblos en cuyos territorios se desarrolló, y que dejó marcas en forma de restos y pertrechos militares, inútiles, olvidados. El topónimo 'Fragmentos de Sapas' alude a los despojos de un avión de combate que pendía de un árbol en medio del bosque. Así pues, los grandes acontecimientos de la región también quedan registrados en el espacio toponímico y, como explica Braunstein (1993), para un wichí conocedor de su herencia cultural recorrer los lugares nombrados es como repasar la historia de su grupo.

Las aldeas 27 de Julio y 28 de Noviembre, fundadas hace menos de 10 años, deben sus nombres a sus respectivos días de fundación. Estos dos nombres ponen de manifiesto una nueva concepción de la historia, donde lo "acontecimental", lo fundacional y la "sedentarización" despiertan un interés que antes no despertaban, y evidencian la fuerte influencia de ciertas modalidades occidentales sobre las wichís. Las toponimias son generalmente conservativas, y tardan en incorporar elementos nuevos (Trapero, 1995). Por eso, puede suponerse que esta "modernización" de la técnica toponímica wichí es el resultado de factores que se dispararon muchas décadas atrás con la colonización criolla de la zona y la llegada de las misiones anglicanas, hacia comienzos del siglo XX (Arenas, 2003 pp. 107125; SAMS, 1940 p. 35). Estos factores son, por ejemplo, la introducción del calendario gregoriano y el establecimiento de los grupos nómadas en aldeas sedentarias.

\section{Relaciones interétnicas}

Aunque para algunos autores los nombres de parentela no definen grupos ni bien delimitados ni bien localizados, se reconoce que, en su función gentilicia, sí definen grupos algo difusos asociados a determinadas zonas (cf. Montani, 2017 pp. 93-105; Palmer, 2005 pp. 118-133). En este sentido, los grupos asociados con el nombre de parentela cigüeñas, se desplazaban por un territorio amplio, con límites poco definidos, que más de una vez se solapaba con el territorio utilizado por otras parentelas o, incluso, por otros grupos étnicos.

A diferencia de la toponimia toba de Pampa del Indio (provincia de Chaco) descripta por Fernández y Braunstein (2001), en la que registraron topónimos que delimitan el territorio de un grupo, en este trabajo no se encontró ningún nombre que aludiera a algún tipo de límite territorial preciso. De hecho, en el trabajo de De la Cruz (1995), que hizo un registro toponímico con colaboradores de 11 aldeas toba cercanas a la zona de estudio, se aprecia una superposición de topónimos toba y wichí, incluso en lugares que hoy son aldeas wichís ('Recipiente de la Sanguijuela' o 'El Quemado'). Esto hace pensar que los grupos tobas y wichís frecuentaban y nombraban los mismos sitios. Sin embargo, muchos de los topónimos 
toba recopilados por De la Cruz son traducciones de los nuevos nombres criollos de esos lugares, de modo que restarían más estudios para dilucidar la posible superposición de topónimos y territorios wichís y tobas.

La distribución diferencial de las dos palabras que existen en wichí para nombrar al agua -inät y waj-es quizá una marca de territorios wichís. Concretamente, en el mapa aparecen tres topónimos con el sustantivo waj, en los extremos Norte ('Agua Profunda'), Este ('Con Agua') y Oeste ('Agua Vieja') de la zona de estudio, mientras que en el Sur y en el centro del territorio aparece inät ('Agua Blanca' y 'El Cansado con el Agua', respectivamente), que es el término que utilizan los habitantes actuales de la zona. Queda como problema abierto determinar si se trata realmente de una isoglosa toponímica, y con qué unidades sociales o dialectales esta isoglosa se correlacionaría.

En las toponimias relevadas por Palmer (2005) y Montani y Juárez (2015), existen topónimos que aluden a enfrentamientos con tobas y nivaclés y a otros tipos de relaciones interétnicas, que básicamente dan cuenta de con quiénes y de qué manera se relacionaban los wichís. En la toponimia carmeña, los vínculos con otros indígenas están mencionados en: el topónimo 'Cadáver de Nivaclé'; dos relatos en los que se narran historias sobre batallas y alianzas con grupos nivaclé y toba ('Chiripa Rota', 'El Quemado'); y en un relato en el que se menciona un problema entre dos grupos wichí ('El Cadáver'). De modo que la toponimia también refleja el carácter fluctuante de las relaciones interétnicas entre los indígenas chaqueños, signadas alternativamente por el enfrentamiento, la tolerancia, la alianza o la simple convivencia (cf. Arenas, 2003 pp. 67-75; Nordenskiöld, 1912/2002 pp. 119-132; Palmer, 2005 pp. 153-164).

Es llamativo que la mayoría de las menciones a otros indígenas sean en torno a enfrentamientos, mientras que no suceda así con los criollos -con quienes aún mantienen graves conflictos. Un único topónimo hace referencia a un conflicto de un grupo de niños wichís con un capataz criollo ('La Boca'). Asimismo, en el mapa están ubicados los pozos de agua y los sitios de vivienda de familias criollas ('Morada de Trasero Pesado', 'Morada de Manito', 'Pozo de Dedo Mocho'), identificadas por el apodo jocoso que los wichís le dieron a alguno de sus integrantes. En ese mismo tono burlesco, ciertos topónimos dan cuenta de la negligencia de los criollos sobre su propio ganado ('Chiquero', 'Cuero del Cebú') y, por último, en el sitio 'La Mujer Hermosa Copula' se recuerda una ofensa al "viborón" por parte de una pareja de criollos que copula en una laguna. En definitiva, salvo por el último topónimo que denuncia una transgresión a una norma social (con consecuencias peligrosas para todos), el resto de las menciones de criollos son burlescas, porque incluso en el sitio 'La Boca', cuyo relato habla de una reacción exagerada y violenta del criollo, el nombre se mofa de su boca golpeada.

\section{Extranjeros en su propio territorio}

En las secciones anteriores mencioné algunos lugares que tienen más de un nombre, ya sea por superposición de nombres entre generaciones de un mismo grupo o entre grupos indígenas distintos. Los nuevos nombres, de origen no indígena, merecen un apartado especial.

Luego de la ocupación y apropiación de los territorios aborígenes por parte del Estado nacional, comenzó un proceso de renombrar los lugares que fueron ocupando los colonos criollos y las distintas congregaciones religiosas. En nuestro repertorio toponímico, de 46 sitios con topónimos criollos, 32 ya contaban con nombres wichí, y muchos de ellos eran sitios de vivienda o de paso, de los que se expulsó a la fuerza a sus legítimos habitantes indígenas. Que se ocupen lugares ya ocupados y nombrados, más allá de cuestiones políticas, tiene que ver también con las condiciones climáticas específicas de la zona. La prolongada sequía y el sol abrasador hacen de los sitios con agua los únicos lugares habitables y, como vimos, los wichís los tienen bien ubicados.

Pero los wichís también renombraron 15 emplazamientos criollos que en principio no tenían un nombre wichí primigenio. En nueve de esos lugares se tradujeron o reinterpretaron los nombres criollos (por ej. calcos lingüísiticos como 'Sombrero Negro' o 'Lecherón', o reinterpretaciones como 'Bebedero de la Vaca'), los seis restantes son puestos o pozos de criollos que se nombran con el apodo otorgado por los wichís a algún residente. El hecho de renombrar lugares bajo sus propios términos, podría ser analizado como un acto de resistencia y de "rehistorización" étnica frente al relato neofundacional criollo (Braunstein, 1993).

En la toponimia oficial de la zona es posible encontrar nombres de lugares que realzan las figuras de militares (Juan Solá, Pozo Sargento o Ramón Lista), y reafirman de alguna manera la potestad del Estado sobre el territorio ocupado. Por otra parte, nombres como el del departamento Matacos, son percibidos como una ofensa para las personas consultadas: "En documento dice Mataco ¿Cómo dice eso mi documento? Cuando hay problema dicen matacos, esa palabra acá no suena cuando viene elección..." (Juan F., Cuaderno de Campo 6, 22-07-2017).

La violencia estatal contra los pueblos indígenas no es "cosa del pasado" ni exclusiva de la zona estudiada, y ha dejado como saldo un genocidio que aún persiste como proceso histórico, material y simbólico (cf. Arenas, 2003 pp. 125-127; Lenton, 2014; Palmer, 2005 pp. 3640). Recientemente hubo dos sentencias judiciales que de algún modo corroboran esta tesitura. El primero fue el reconocimiento de la "masacre de Rincón Bomba" como delito de lesa humanidad por los tribunales 
federales (Aranda, 2019); y el segundo fue un fallo de la Corte Interamericana de Derechos Humanos que obliga al Estado nacional a reconocer la propiedad de las tierras a 132 comunidades indígenas (Corvalan, 2020). Los resultados de estas acciones se percibirán en el futuro, aunque con los antecedentes existentes, no es de esperar que la situación de abandono y pobreza en la cual viven actualmente en estas aldeas se modifique sustancialmente. Sin embargo, sienta un precedente legal que puede ser utilizado para futuros reclamos $y$, de cumplirse las sentencias, algunas tierras serán devueltas a los pueblos indígenas.

\section{Palabras finales}

La toponimia de los carmeños conjuga muchos mapas en un solo mapa. El económico, pues indica lugares donde encontrar alimentos, agua y materias primas para diversas industrias (textil, alfarera). El ecológico, pues da cuenta de un profundo conocimiento de los ciclos vitales de diversas especies, de los ciclos de elementos inorgánicos, y evoca también las conexiones entre lo vivo y lo no vivo. El religioso, pues en él figura el chamanismo y ciertas entidades metafísicas, y sitúa las antiguas misiones. El social, puesto que ubica los sitios de vivienda, recuerda ciertas personalidades destacadas, da cuenta de las relaciones interétnicas y alude a valores morales. El histórico, ya que destaca los sucesos locales y regionales que influyeron en la vida de los wichís. Y, finalmente, el mapa educativo, que con los dramas que evoca o con ese humor sutil y tímido que suscita -tan característico de los wichís- brinda advertencias y recomendaciones para afrontar la vida (cf. Palmer 2005 p. 77). En definitiva, es mucho más que un mapa.

Esta cualidad de entretejer tantos elementos disímiles se relaciona con una manera de comprender y vivir el territorio. El sistema toponímico wichí no es una descripción fidedigna y objetiva del paisaje, es su representación social, conservada en la memoria colectiva, transmitida oralmente, vivida en el día a día $y$, por todo ello, una representación que se encuentra atravesada por todas las esferas de la experiencia humana.

Por último, la toponimia carmeña no está muerta ni es un resabio de tiempos pasados, por el contrario, tanto en la diversidad de sus conceptos como en su renovación y adaptación a las condiciones cambiantes de la historia, se muestra vigorosa. Son muchos los elementos culturales novedosos incorporados en los topónimos, principalmente por la influencia de la cultura criolla; pero todos pasan por el tamiz étnico de los wichí que, como los topónimos, resiste y proclama su vitalidad. Defender el territorio y la toponimia es, pues, defender la memoria, la identidad y la vida.

Córdoba, 5 de mayo de 2020

\section{Agradecimientos}

Agradezco profundamente por toda su generosidad a las personas de Fwis-hi y To $Y^{\prime}$ o y del barrio Palo Santo de Ingeniero Juárez. Otro agradecimiento especial a Rodrigo Montani por sus comentarios y contribuciones, y también a quienes colaboraron y apoyaron de otras maneras: Pastor Arenas, Bárbara Arias Toledo y Agustín Aguirre.

\section{Bibliografía}

Aranda, D. (2019, julio 5). La masacre pilagá fue declarada crimen de lesa humanidad. Página 12. https:// www.pagina12.com.ar/204582-la-masacre-pilaga-fuedeclarada-crimen-de-lesa-humanidad.

Arenas, P. (1997). Las bromeliáceas textiles utilizadas por los indígenas del Gran Chaco. Parodiana, 10, 113-139.

Arenas, P. (2003). Etnografía y alimentación entre los Toba-Ñachilamole\#ek y Wichí-Lhuku'tas del Chaco Central (Argentina). Buenos Aires: El autor.

Biblia Wichí. (2002). Dios Lhämtes tä Matchehen: La Biblia en idioma wichí. Brasil: SBA y SBU.

Braunstein, J. A. (1993). Territorios e historia de los narradores matacos. Hacia una nueva carta étnica del Gran Chaco, 5, 4-74.

Buliubasich, C., Drayson, N. y Molina de Bertea S. (2004). Las palabras de la gente. Alfabeto unificado para wichi Ihämtes. Proceso de consulta y participación. Salta: CEPIHA.

Censabella, M. (2009). Denominaciones etnonímicas y toponímicas tobas: Introducción a la problemática y análisis lingüístico. Hacia una nueva carta étnica del Gran Chaco, 8, 213-236.

Chapin, M., Lamb, Z., y Threlkeld, B. (2012). Mapeo de tierras indígenas. En C. Salamanca y R. Espina (Comps.), Mapas y Derechos: experiencias y aprendizas en América Latina (pp. 13-49). Rosario: Universidad Nacional de Rosario.

Claesson, K. (2008). Notas sobre el vocabulario 'weenhayek. Cochabamba: SBB.

Corvalan, E. (2020, abril 2). La Corte Interamericana le dio a la razón a comunidades indígenas. Página 12. https:// www.pagina12.com.ar/257060-la-corte-interamericanale-dio-a-la-razon-a-comunidades-indi.

De la Cruz, L. M. (1995). Qomlajépi naleua, nuestra tierra. Los sitios que contienen la tierra que da vida a los tobas de Sombrero Negro de la provincia de Formosa. Hacia una nueva carta étnica del Gran Chaco, 6, 69-116. 
Dell'Arciprete, A. (1991). Lugares de los pilagá. Hacia una nueva carta étnica del Chaco, 2, 58-85.

Fabre, A. (2005). Los pueblos del Gran Chaco y sus lenguas, segunda parte: Los mataguayo. Suplemento Antropológico, 40, 313-435.

Fernández, A., y Braunstein, J. (2001). Historias de Pampa del Indio. En IV Congreso Argentino de Americanistas, Vol. 2 (pp. 161-193). Dunken. Buenos Aires: Sociedad Argentina de Americanistas.

Iriondo, M. (2006). Cambios ambientales en el Chaco argentino y boliviano en los últimos miles de años. Folia Histórica del Nordeste, 16, 39-49.

Lenton, D. (2014). Apuntes en torno a los desafíos que derivan de la aplicación del concepto de genocidio en la historia de las relaciones entre el estado argentino y los pueblos originarios. En J. L. Lanata (Comp.), Prácticas genocidas y violencia estatal en perspectivas transdiciplinar (pp. 32-51). San Carlos de Bariloche: IIDYPCa-CONICET.

Lunt, R. M. (2016). Diccionario de la lengua wichí: Wichí - Español. Ciudad Autónoma de Buenos Aires: Sociedad Bíblica Argentina.

Martínez Crovetto, R. N. M. (1995). Zoonimia y etnozoología de los pilagá, toba, mocoví, mataco y vilela. Ciudad Autónoma de Buenos Aires: Instituto de Lingüística, Facultad de Filosofía y Letras, Universidad de Buenos Aires.

Matarrese, M. L. (2019). Política indigenista en materia territorial (Formosa, Argentina). Revista mexicana de sociología, 81(3), 583-610.

Montani, R. (2017). El mundo de las cosas entre los wichís del Gran Chaco. Un estudio etnolingüístico. Cochabamba: Itinerarios Editorial y $\mathrm{CIHA}$.
Montani, R., y Juárez, G. (2015). Los días del pasado. Historias de los wichí de Morillo, San patricio, Los Baldes. Mahnayay ta iyejen p'ante wichi ta yhi Muliyus San Patlisyu Ihoya Kale-hí. Córdoba: Ediciones La Marmosa.

Nordenskiöld, E. (2002). La vida de los indios. Bolivia: APCOB. (Trabajo original publicado en 1912).

Palmer, J. H. (1995). Wichi toponymy. Hacia una nueva carta étnica del Gran Chaco, 6, 3-63.

Palmer, J. H. (2005). La buena voluntad wichí: Una espiritualidad indígena. Buenos Aires: Grupo de trabajo Ruta 81.

Salamanca, C. (2012). Memoria, acción colectiva y narrativas territoriales: paradojas y desafíos de la cartografía social en Argentina. En C. Salamanca y R. Espina (Comps.), Mapas y Derechos: experiencias y aprendizas en América Latina (pp. 141-194). Rosario: Universidad Nacional de Rosario.

SAMS (South American Missionary Society). (1940). Annual Report 1940. Londres: SAMS.

Sletto, B. I., Bryan, J., Torrado, M., Hale, C., y Barry, D. (2013). Territorialidad, mapeo participativo y política sobre los recursos naturales: la experiencia de América Latina. Cuadernos de Geografía: revista colombiana de geografía, 22(2), 193-310.

Suárez, M. E. (2014). Etnobotánica wichí del bosque xerófito en el Chaco Semiárido salteño. Don Torcuato: Autores de Argentina.

Trapero, M. (1995). Para una teoría lingüística de la toponimia (Estudios de toponimia canaria). Gran Canaria: Universidad de Las Palmas.

Wright, P. (1991). Topónimos de la zona de Misión Tacaaglé (Formosa). Hacia una nueva carta étnica del Gran Chaco, 2, 41-57. 